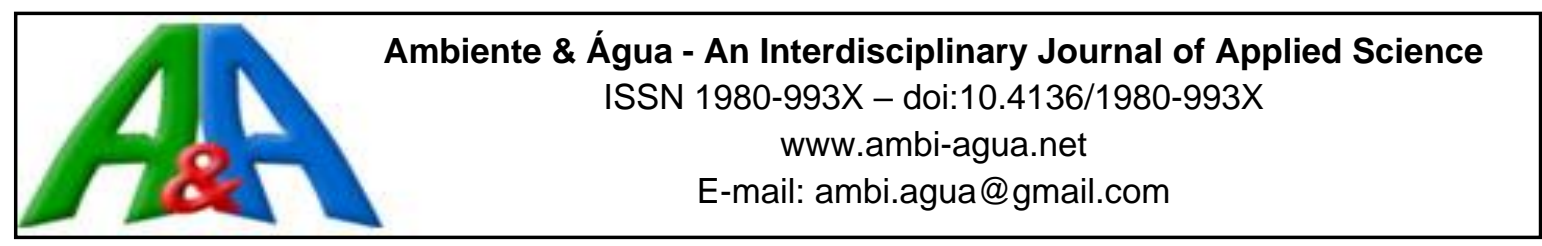

\title{
Avaliação de bacia hidrográfica por alunos do Ensino Fundamental: contribuição ao ensino dos recursos hídricos ${ }^{1}$
}

\author{
doi:10.4136/ambi-agua.1895
}

Received: 10 Oct. 2016; Accepted: 10 Nov. 2016

\author{
Cheila Flávia de Praga Baião ${ }^{*}$; Getulio Teixeira Batista ${ }^{1}$ \\ ${ }^{1}$ Universidade de Taubaté (UNITAU), Taubaté, SP, Brasil \\ Programa de Pós-Graduação em Ciências Ambientais \\ *Autor correspondente: e-mail: cheilabaiao77@gmail.com, \\ gtbatista@gmail.com
}

\section{RESUMO}

Neste trabalho, um protocolo de avaliação rápida (PAR) foi desenvolvido e testado em uma bacia hidrográfica inserida na Bacia do Rio Paraíba do Sul, para ser aplicado por alunos do Ensino Fundamental. O estudo foi realizado em uma Escola Estadual de São José dos Campos (SP) e envolveu 60 alunos do $6^{\circ}$ ano $(n=30)$ e do $7^{\circ}$ ano $(n=30)$. O protocolo elaborado contém 12 parâmetros, com texto acessível ao nível escolar e ilustrações das variáveis de cada parâmetro. Os parâmetros são: tipo de ocupação das margens d'água, erosão e assoreamento, presença de esgoto, presença de plantas aquáticas, odor da água, oleosidade da água, transparência da água, tipo de fundo, corredeiras e fluxos d'água, presença de lixo, presença de animais e presença de mata ciliar. Os resultados apontaram que $65 \%$ dos alunos compreenderam bem todos os parâmetros analisados e apresentaram grande interesse pelo protocolo proposto, os demais precisaram compreender melhor os parâmetros de erosão e assoreamento, presença de plantas aquáticas, corredeiras e fluxos d'água, e presença de mata ciliar. Verificou-se que o PAR foi adequado e pode contribuir como instrumento didático de estudo dos recursos hídricos.

Palavras-chave: educação ambiental, instrumento didático, protocolo de avaliação rápida.

\section{Watershed evaluation by elementary school students: contribution to water resources teaching}

\begin{abstract}
This work developed and tested a rapid assessment protocol (RAP) in a watershed of the Paraíba do Sul River Basin, to be applied by elementary school students. The study was conducted in a public school of São José dos Campos (SP), with 60 students of the $6^{\text {th }}$ grade $(\mathrm{n}=30)$ and $7^{\text {th }}$ grade $(\mathrm{n}=30)$. The protocol developed includes 12 parameters with text consistent with student levels and with illustrations of the variables of each parameter. The parameters are the type of usage of the stream margins, erosion and siltation, presence of sewage, presence of aquatic plants, water odor, water oiliness, water transparency, type of bottom, rapids and water flow, garbage presence, the presence of animals, and the presence of
\end{abstract}

${ }^{1}$ Artigo derivado de parte da dissertação de mestrado da primeira autora defendida no Programa de Pós Graduação em Ciências Ambientais da Universidade de Taubaté, SP, Brasil, em 2014. 
riparian vegetation. The results showed that $65 \%$ of the students understood all parameters and showed great interest in the proposed protocol; the others needed to better understand the parameters of erosion and siltation, presence of aquatic plants, rapids, water flow and presence of riparian vegetation. It was found that the developed RAP was appropriate and can contribute as an educational tool for the study of water quality.

Keywords: assessment protocol, environmental education, teaching tool.

\section{INTRODUÇÃO}

A gestão das águas no Brasil tem como unidade territorial a bacia hidrográfica conforme estabelecida na Política Nacional de Recursos Hídricos (Brasil, 1997). Esta unidade natural possibilita uma visão sistêmica e integrada, envolvendo processos climatológicos, hidrológicos, geológicos e ecológicos com interações antrópicas, econômicas e sociais nos processos biogeofísicos (Lucatto e Talamoni, 2007). Por sua natureza complexa, é uma unidade física ideal para manejo e gestão ambiental (Schiel et al., 2002).

A gestão dos recursos hídricos, segundo Porto e Porto (2008), para ser sustentável precisa disponibilizar informações para a sociedade, de forma que os limites impostos pela aptidão natural das bacias hidrográficas sejam respeitados. Estas informações podem advir de projetos de Educação Ambiental, incentivando a promoção da participação social, previstos nos planos de gerenciamentos de bacias hidrográficas, como por exemplo, o Plano de Bacia do Rio Paraíba do Sul, com recursos do Fundo Estadual de Recursos Hídricos do Estado de São Paulo FEHIDRO (COPPETEC, 2007).

O conceito de educação ambiental (EA) é entendido no contexto da Política Nacional de Educação Ambiental, como os processos por meio dos quais o indivíduo e a coletividade constroem valores sociais, conhecimentos, habilidades, atitudes e competências voltadas para a conservação do meio ambiente (Brasil, 1999). É um processo no qual são trabalhados compromissos e conhecimentos capazes de levar o indivíduo a repensar sua relação com o meio (Schiel et al., 2002). Para Jacobi (2003), a EA tem uma função transformadora, tendo como objetivo essencial a corresponsabilização dos indivíduos na promoção do desenvolvimento sustentável. Os Parâmetros Curriculares Nacionais (PCNs) do Meio Ambiente tratam a EA como meio indispensável para se conseguir criar e aplicar formas cada vez mais sustentáveis de interação sociedade/natureza e para isso deve-se trabalhar os vínculos de identidade com o entorno socioambiental (Brasil, 1998).

Schiel et al. (2002) colocaram as unidades escolares como os mais legítimos canais a serem utilizados, por serem fontes de formação e produção de conhecimento. Assim, a Escola pode ser um espaço propício para análise da natureza em um contexto entrelaçado de práticas sociais de uma realidade complexa e que deve fazer parte de cada aluno (Jacobi, 2003). Nas áreas urbanas, programas de Educação Ambiental podem aumentar a percepção local dos alunos, permitindo que visualizem a legitimidade e a utilidade dos aspectos ecológicos da paisagem (Kudryavtsev et al., 2012).

Dentro deste princípio diversos autores como Schiel et al. (2002), Callisto (2002), Batista et al. (2005), Scatena (2005), Bergman e Pedrozo (2008) e Guimarães et al. (2012) exploraram a bacia hidrográfica, envolvendo professores, estudantes e comunidades, por meio de um estudo das condições ambientais desta unidade territorial em que foram explorados conhecimentos sobre solo, relevo, geologia, vegetação, fauna, clima, impactos antrópicos e possibilidades de recuperação. Conceitos que exemplificam as relações e dinâmicas ambientais terrestres, o que segundo Tundisi (2008), são necessários para contribuir para uma verdadeira educação da comunidade e de futuros gestores com novas abordagens.

\section{IPABH}

Rev. Ambient. Água vol. 11 (suplemento) Taubaté, 2016 
Dentre os instrumentos utilizados para monitoramento da bacia hidrográfica destacam-se os protocolos de avaliação rápida - PAR. Estes instrumentos começaram a ser desenvolvidos na década de 80, por órgãos internacionais, como a Agência de Proteção Ambiental dos Estados Unidos (EPA). Possibilitam uma avaliação holística do ambiente e permitem a inserção da comunidade na gestão dos recursos hídricos, tanto por abranger um segmento social, quanto pelos custos reduzidos (Rodrigues e Castro, 2008).

Os PARs são instrumentos de avaliação constituídos por um conjunto de parâmetros, os quais permitem a avaliação das características físicas e nível de impactos ambientais decorrentes de atividades antrópicas, bem como as condições de conservação natural (Callisto et al., 2002).

A elaboração de um PAR exige que indicadores ambientais sejam criteriosamente desenvolvidos de acordo com a proposta de monitoramento a ser seguida, respeitando as características de cada bacia hidrográfica, devendo ser complementados e adequados em um processo contínuo de ajustes e aprimoramentos que levem em conta o clima, o relevo, a geologia e a vegetação (Rodrigues e Castro, 2008). Os protocolos de avaliação rápida de trechos de bacia hidrográfica são adequados também aos projetos de educação ambiental, pois atendem a essas premissas (Schiel et al. 2002; Jacobi, 2003).

Dessa forma, almejando ampliar a concepção ambiental pela compreensão das diversas interações que ocorrem numa bacia, nas dimensões humanas, ecológicas e físicas, o objetivo deste estudo foi desenvlover um protocolo de avaliação rápida de trechos de bacia hidrográfica para ser aplicado por alunos do Ensino Fundamental, contribuindo como instrumento didático de estudo dos recursos hídricos.

\section{MATERIAIS E MÉTODO}

O estudo envolveu alunos da faixa etária entre 10 e 12 anos, matriculados $6^{\circ}$ e $7^{\circ}$ anos do Ensino Fundamental de uma escola estadual localizada em São José dos Campos. A amostra de estudo contemplou 60 crianças, sendo 30 do $6^{\circ}$ ano (16 meninas e 14 meninos) e 30 do $7^{\circ}$ ano (15 meninos e 15 meninas), correspondente a uma classe de cada ano. $O$ percentual da amostra é de $12,5 \%$ do total de alunos desses anos do Ensino Fundamental. A pesquisa foi aprovada pelo Comitê de Ética em Pesquisa (CEP) da Universidade de Taubaté ( ${ }^{\circ}$ do CAAE: 11407912.5.0000.5501) em 12 de abril de 2013.

A bacia escolhida para estudo é a mais próxima da escola, pertencendo à Bacia do Rio Comprido, sub-bacia do Rio Paraíba do Sul. Está localizada na divisa entre os municípios de São José dos Campos e Jacareí e está sob o impacto da expansão urbana, com forte degradação socioambiental (Makinodan e Costa, 2004). Ela é subentendida pelas seguintes coordenadas:

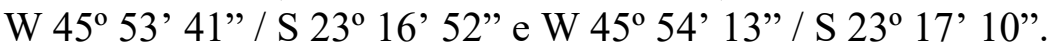

Os procedimentos metodológicos iniciaram-se com a conceituação de bacia hidrográfica, por meio de uma apresentação disponibilizada em: http://prezi.com/d47apunyln07/baciahidrografica/, de acordo com as recomendações de Shepardson et al. (2007) e pela construção da cobertura da bacia de estudo, utilizando papel vegetal e uma imagem do satélite Quickbird de 2010 de acordo com orientações de Florenzano (2007).

Os procedimentos metodológicos para elaboração e aplicação do PAR estão sumariados na Figura 1.

Neste trabalho, o PAR proposto foi baseado em diversos trabalhos anteriores incluindo Callisto et al. (2002), Scatena (2005), Bergmann e Pedrozo (2008), e Guimarães et al. (2012), selecionando-se os parâmetros que melhor se adaptavam às características da bacia de estudo.

Como o PAR constitui uma análise quanti-qualitativa do ambiente, visto que o monitoramento depende dos conhecimentos do avaliador e da sua capacidade de percepção (Rodrigues e Castro, 2008), tentou-se deixar o protocolo o mais claro e acessível ao nível 
escolar dos alunos, utilizando em cada parâmetro, uma linguagem adequada e ilustrações coloridas.

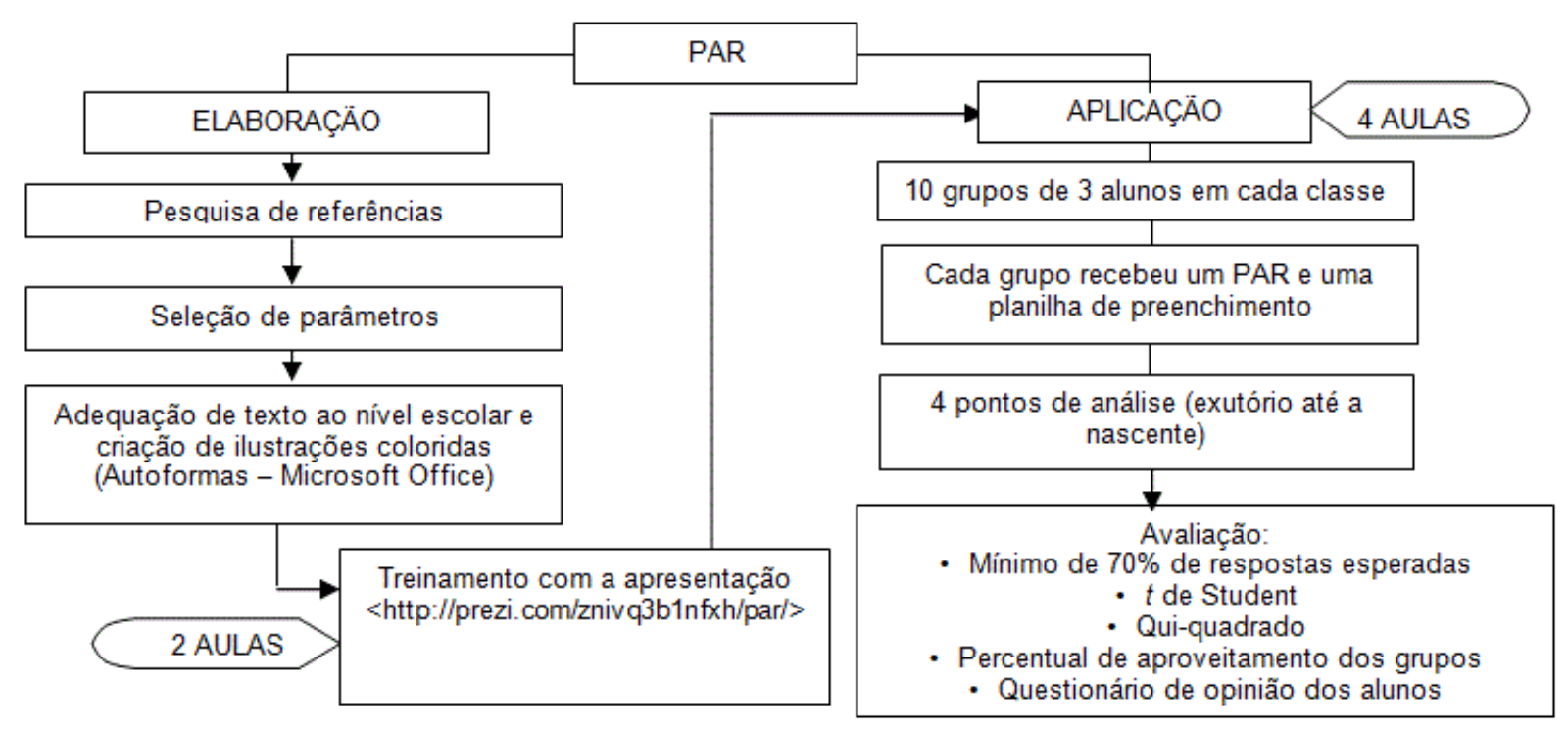

Figura 1. Fluxograma da elaboração e aplicação do Protocolo de Avaliação Rápida (PAR) com o número de aulas em cada atividade ( 1 aula $=50 \mathrm{~min})$.

Fonte: Baião (2014).

Os parâmetros selecionados para este Protocolo foram: Tipo de ocupação das margens d'água, erosão e assoreamento, presença de esgoto, presença de plantas aquáticas, odor da água, oleosidade da água, transparência da água, tipo de fundo, corredeiras e fluxos d'água, presença de lixo, presença de animais e presença de mata ciliar.

Os parâmetros são pontuados por notas pré-estabelecidas correspondentes ao estado de conservação do ambiente (Rodrigues e Castro, 2008). Portanto, para os 12 parâmetros selecionados, atribuiu-se a pontuação " 0 " para trechos impactados, "3" para trechos alterados e "5" para trechos naturais (não alterados). A somatória dos valores atribuídos a cada parâmetro classifica os trechos observados em impactados, alterados ou naturais (Bergmann e Pedroso, 2008). O gradiente de classificação do ambiente foi determinado utilizando-se um percentual aproximado de pontuação para trechos impactados, alterados e naturais, com base em Callisto et al. (2002), Scatena (2005), Bergmann e Pedrozo (2008) e Guimarães et al. (2012) e ponderouse com o estado de conservação observado (Guimarães et al., 2012) e com as características próprias da bacia estudada. Desta forma, estabeleceu-se: zero a 25 pontos correspondem a trechos impactados, 26 a 40 pontos a trechos alterados e 41 a 60 pontos a trechos naturais.

Para a aplicação do protocolo proposto, a bacia foi dividida em 4 pontos de análise, escolhidos de acordo com a facilidade de acesso e a distância entre eles, organizando o trajeto em uma topossequência. O ponto 1 (Figura 2, P1) da Bacia de estudo está localizado no exutório com muito acúmulo de sedimento. Nele podem ser observados processos de erosão e assoreamento. As margens são cobertas por vegetação rasteira. $O$ curso d'água apresenta uma fina lâmina com correnteza baixa e há presença moderada de plantas aquáticas. O ponto 2 (Figura 2, P2) é caracterizado pela presença de uma escada hidráulica que sofreu desmoronamentos, tendo muitos pedaços de concreto espalhados pelo leito. As margens são vegetadas por gramíneas, com lixo e entulho espalhados. Apresenta odor desagradável. O ponto 3 (Figura 2, P3) apresenta arbustos, característicos de vegetação pioneira, entremeados por gramíneas. A jusante é represada para utilização como balneário. Parte das margens tem solo exposto e em alguns trechos há macrófitas. O ponto 4 (Figura 2, P4) é o local mais próximo da

\section{IPABH}


nascente que foi possível se chegar com os alunos. A vegetação a montante é arbórea e a jusante possui vegetação arbustiva e herbácea em área alagada.

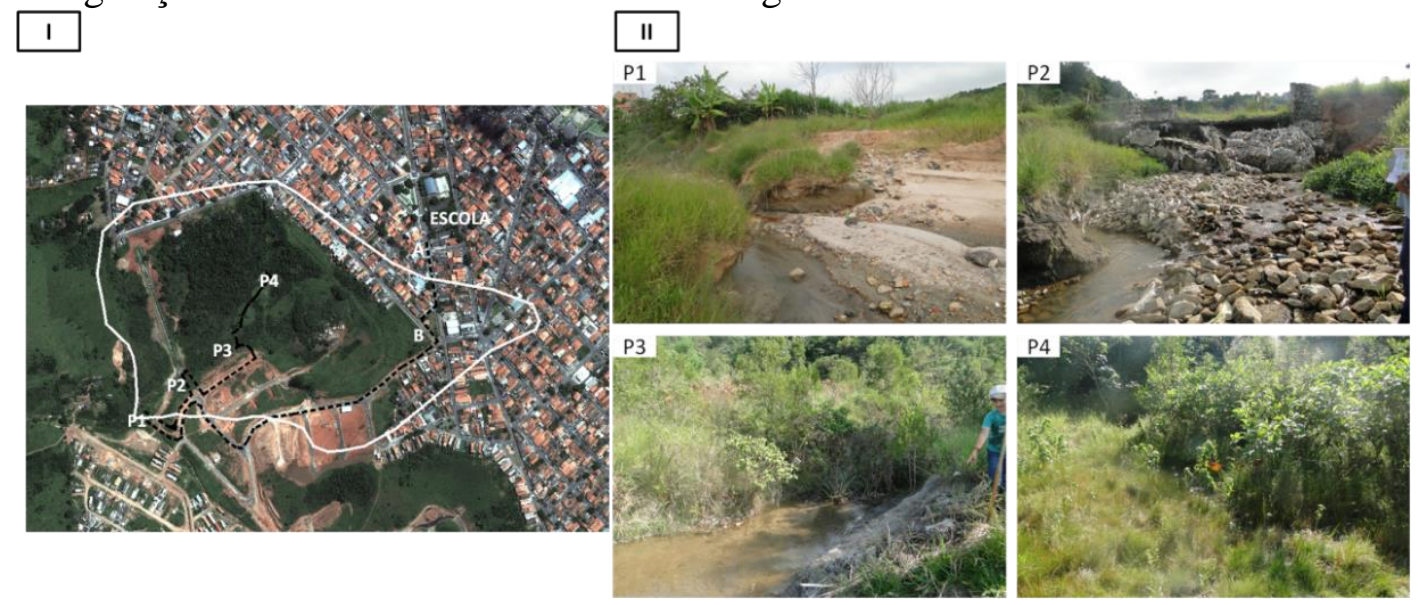

Figura 2. I- Limite da bacia de estudo em branco e trajeto percorrido pelos alunos em pontilhado preto, na sequência: A- saída da escola; B - Visão panorâmica da bacia; P1 - Ponto

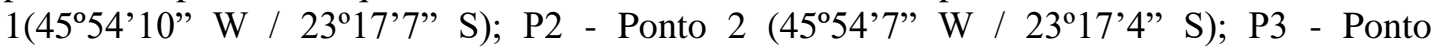

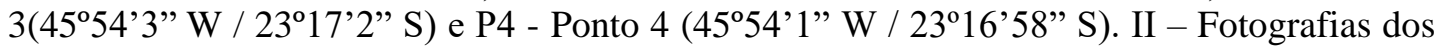
pontos de análise: P1 - exutório da bacia; P2 - escada hidráulica; P3 - balneário e P4 nascente.

Fonte: Baião (2014).

Os $6^{\circ}$ e $7^{\circ}$ anos participaram da atividade em dias diferentes, para facilitar o trabalho com um número menor de alunos. As classes foram divididas em grupos de 3 alunos, constituindo 10 grupos em cada classe e 20 no total. A formação dos grupos ocorreu de forma aleatória de acordo com afinidade entre os participantes. Todos os grupos aplicaram o PAR nos 4 pontos.

Os resultados foram analisados quantitativamente por meio de cálculos estatísticos com base teórica em Vieira (2008). Para se avaliar as diferenças entre as duas séries na interpretação dos parâmetros foi utilizado o teste $t$ de Student e para se verificar eventuais parâmetros não compreendidos pelos grupos de alunos, inovou-se neste estudo utilizando o Qui-quadrado de Pearson.

A determinação da frequência esperada para o teste do Qui-quadrado de Pearson, ocorreu admitindo-se que cada parâmetro deveria ter no mínimo $70 \%$ dos 20 grupos de alunos $(\mathrm{n}=14)$ atribuindo notas esperadas; o máximo de $25 \%$ dos 20 grupos $(\mathrm{n}=5)$ atribuindo notas próximas à nota esperada; e o máximo de $5 \%$ dentre os 20 grupos $(n=1)$ atribuindo notas que não são esperadas e nem próximas às esperadas. As notas esperadas são notas cujo valor representa a real condição ambiental do local estudado de acordo com o parâmetro avaliado. Portanto, se dentro de um determinado parâmetro, o local estiver impactado, deve receber nota " 0 "; se estiver alterado, nota " 3 " e se estiver natural, nota " 5 ". As notas esperadas foram determinadas por uma aplicação prévia do protocolo proposto feita pela autora principal deste artigo. Estabeleceu-se o percentual mínimo de $70 \%$ para notas esperadas, por entender que este percentual é representativo e superior à média exigida nas escolas públicas estaduais que é de $50 \%$. As notas próximas à nota esperada são notas cujo valor é próximo do valor da nota esperada. Assim, se a nota esperada é " 5 ", admitiu-se $25 \%$ de notas " 3 "; se a nota esperada é “3", admitiu-se $25 \%$ de notas " 0 " ou " 5 " dependendo do nível de alteração do ambiente, avaliado de acordo com a aplicação prévia feita pela autora principal; e se a nota esperada for " 0 ", aceitou-se $25 \%$ de notas " 3 ".

Para mapear a percepção dos grupos sobre o ambiente estudado, foi calculado o percentual de acertos de cada grupo, em cada parâmetro e em cada ponto. Os acertos foram medidos atribuindo-se $100 \%$ a cada resposta esperada, $30 \%$ para a resposta cujo valor é próximo do valor 
da nota esperada e zero para a resposta que não se aplicaria. Este percentual de $30 \%$ foi atribuído arbitrariamente para representar que o mínimo de $70 \%$ estabelecido por esta metodologia não foi atendido, no entanto pode representar o início da compreensão que se espera.

As opiniões dos estudantes sobre o PAR foram avaliadas por meio de um questionário adaptado de Guimarães et al. (2012): 1 - As instruções dadas em sala de aula ajudaram na melhor compreensão do PAR?; 2 - Durante a avaliação da bacia hidrográfica com o protocolo, você se sentiu um agente colaborador na defesa de um rio?; 3 - Você apresentou alguma dificuldade de entendimento dos parâmetros propostos no PAR?; 4 - Você acredita que a utilização do protocolo é um meio que o aproxima das questões ambientais?; 5 - As ilustrações disponíveis em cada parâmetro o ajudaram durante a avaliação em campo e durante a atribuição de notas aos parâmetros?; 6 - A participação nesta atividade de monitoramento ambiental permitiu maior conhecimento sobre os elementos e interações presentes numa bacia hidrográfica?; e 7 - Você acredita que qualquer pessoa previamente treinada pode realizar a avaliação de uma bacia hidrográfica utilizando este PAR?

As percentagens das respostas positivas e negativas do questionário foram contabilizadas.

Em sala de aula, de posse de suas planilhas de resultados, preenchidas em campo, os alunos se reuniram em grupos e fizeram um levantamento dos parâmetros que eles não atribuíram nota 5 (natural). Em seguida foi solicitado que sugerissem ações de melhoria para os parâmetros considerados impactados ou alterados.

\section{RESULTADOS E DISCUSSÃO}

O protocolo de avaliação rápida para aplicação nesta pesquisa está representado na Figura 3.

A análise pelo teste t de Student revelou que os $6^{\circ}$ e $7^{\circ}$ anos tiveram em média a mesma compreensão do protocolo. O Valor $t$ encontrado para cada ponto estudado (Ponto 1: 1,598; Ponto 2: 1,969; Ponto 3: 0,954 e Ponto 4: 0,42), está abaixo do $t$ crítico de 2,12, para significância de $5 \%$, comprovando hipótese nula de que alunos de $6^{\circ}$ e $7^{\circ}$ anos apresentam em média as mesmas compreensões, permitindo a análise conjunta dos dados das duas séries.

A variação das notas atribuídas pelos 20 grupos de alunos em cada ponto de análise pode ser observada na Figura 4. Pode-se verificar que a maior concentração de notas está dentro dos intervalos esperados para cada ponto (ponto 1 - exutório ao ponto 4 - nascente). De acordo com o PAR proposto neste trabalho, o ponto 1 (Figura 2) está classificado como um trecho altamente alterado. O ponto 2 (Figura 2) está impactado. O ponto 3 (Figura 2) atinge pontuação para natural, mas apenas pela diferença de 1 ponto. O ponto 4 (Figura 2) atinge uma pontuação dentro do intervalo considerado natural.

Dos parâmetros relatados acima, erosão e o assoreamento também foram conceitos de difícil compreensão pelos alunos nos estudos realizados por Callisto et al. (2002), Guimarães et al. (2012) e Scatena (2005).

Corredeiras, fluxos d'água e presença de plantas aquáticas também foram reportados por Scatena (2005) com grande variação de repostas, indicando incertezas no conceito. Como as macrófitas são indicadoras de excesso de matéria orgânica, advinda do esgoto ou do escoamento dos dejetos da criação animal, os alunos se confundiram achando que plantas aquáticas são prejudiciais. Assim sendo, foi importante ressaltar sua função ecológica de purificação da água sendo, inclusive, algumas espécies de plantas aquáticas utilizadas como fitorremediadoras de áreas contaminadas com coliformes (Curutchet et al., 2011).

O tipo de fundo no ponto 2 não teve boa avaliação para $35 \%$ dos grupos $(n=7)$. Possivelmente, pela presença de uma escada hidráulica e diversas estruturas desmoronadas, cobrindo trechos do corpo d'água com pedras de concreto, associadas à presença de areia a montante do ponto, pode ter gerado uma variação de respostas não esperadas. Tal parâmetro

\section{IPABH}


também apresentou resultados não esperados em $50 \%$ dos grupos trabalhados por Scatena (2005).
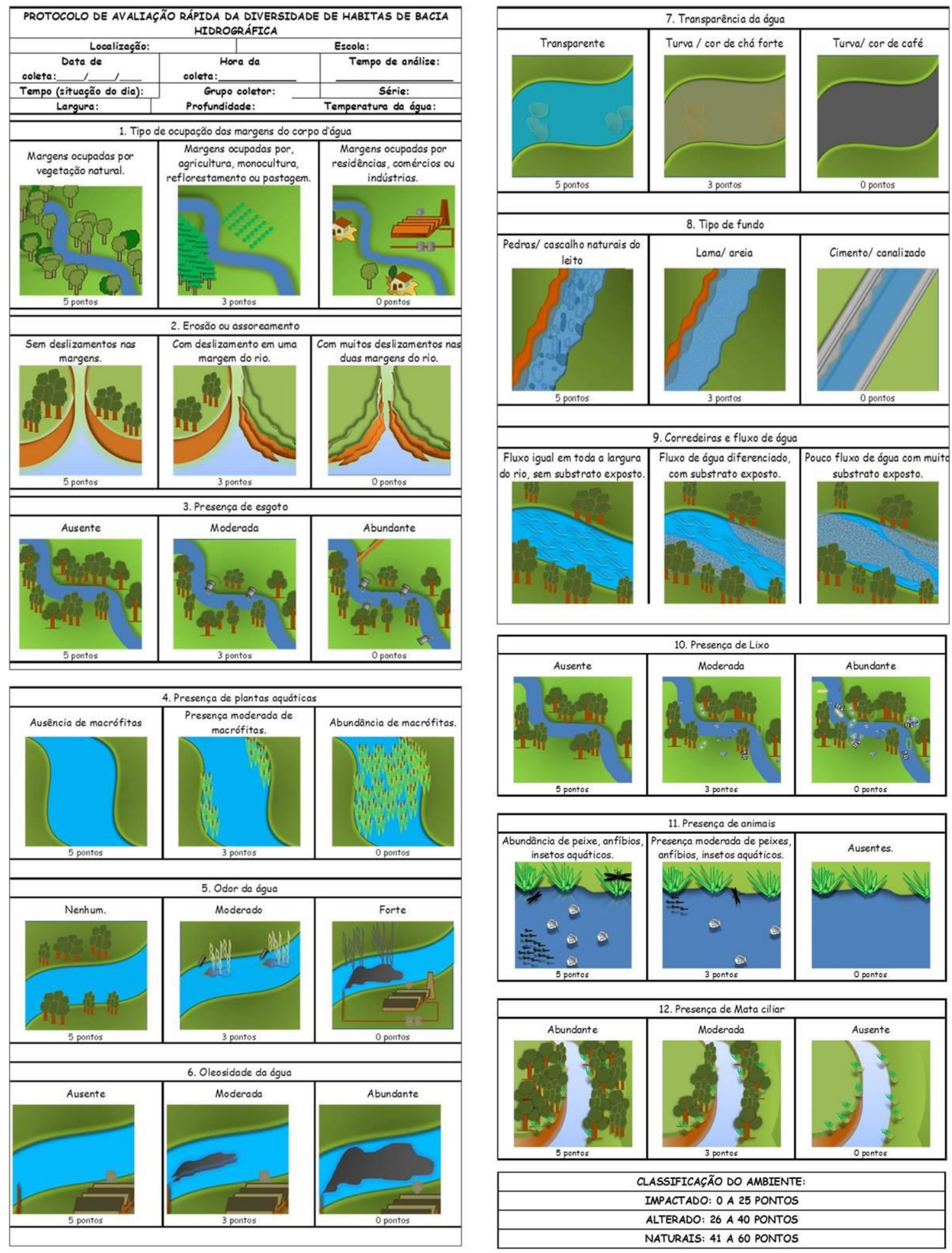

Figura 3. Protocolo de avaliação rápida de pontos da bacia hidrográfica. Trechos impactados: 0 a 25 pontos; trechos alterados: 26 a 40 pontos e trechos naturais: 41 a 60 pontos.

Fonte: Baião (2014). 


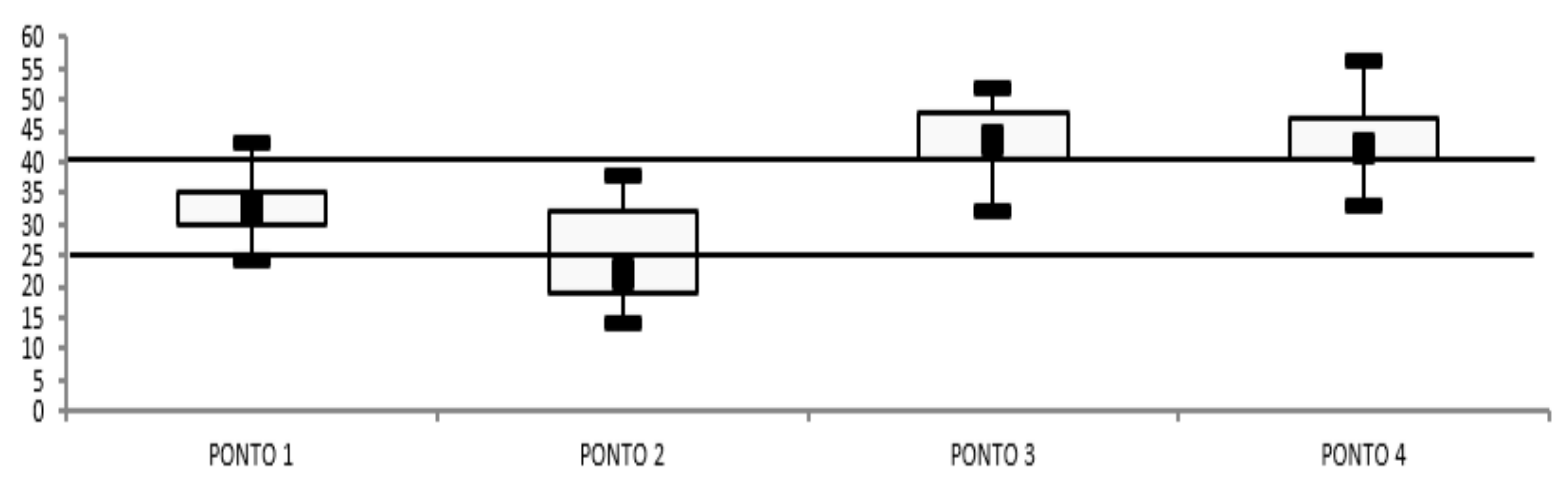

Figura 4. Boxplot da variação da pontuação total atribuída em cada ponto pelas duas turmas em análise (Mínimo, $1^{\circ}$ quartil, mediana, $3^{\circ}$ quartil e máximo). As linhas sinalizam os intervalos de pontuação para trechos impactados ( 0 a 25$)$, alterados (26 a 40) e naturais (41 a 60).

Fonte: Baião (2014).

De acordo com o teste do Qui-Quadrado, os parâmetros cujas respostas dos alunos não atenderam à frequência esperada (Figura 5) foram: Erosão e assoreamento, Presença de plantas aquáticas, Tipo de Fundo, Corredeiras e Fluxo de água, Lixo e Presença de Mata Ciliar.

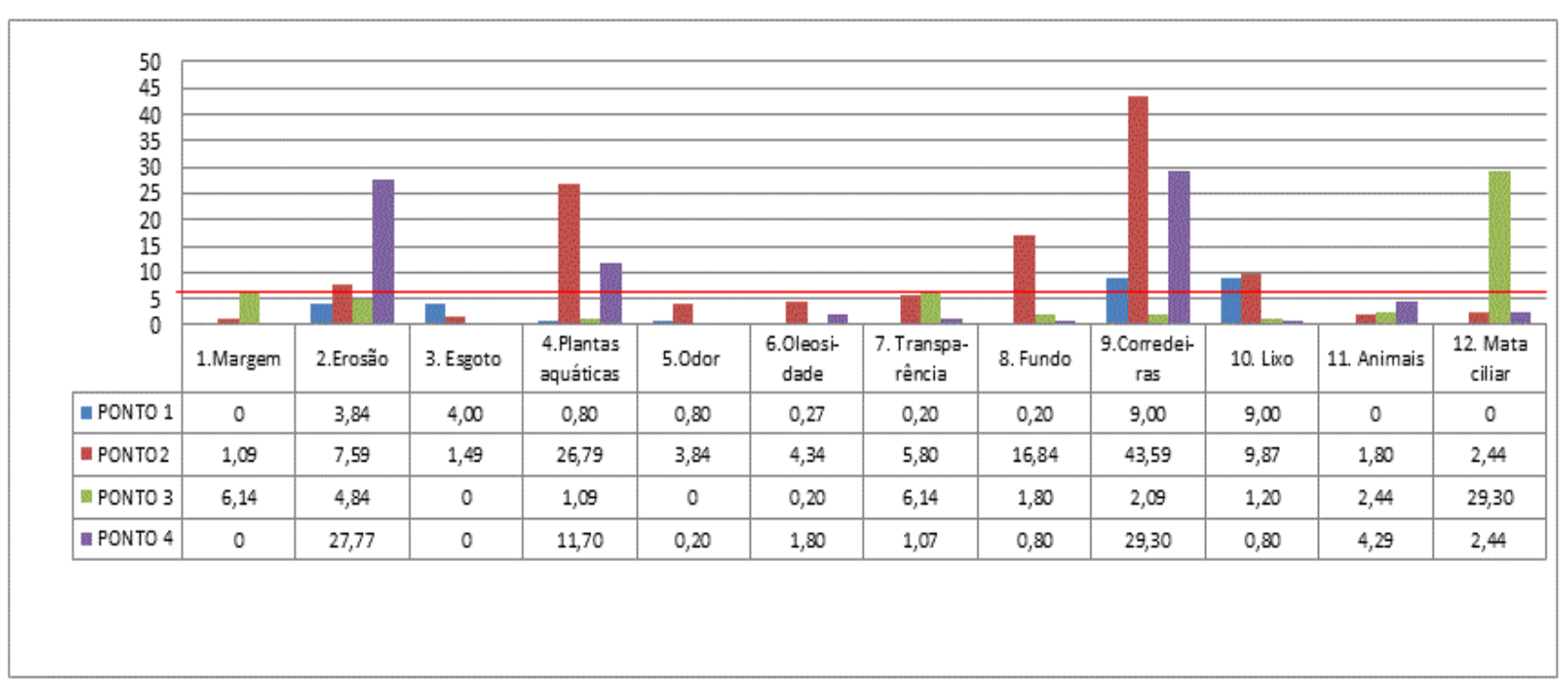

Figura 5. $X^{2}$ de Pearson para os 12 parâmetros analisados nos 4 pontos analisados. Grau de liberdade 2, $\alpha$ $5 \%=5,99$, representado por linha vermelha.

Fonte: Baião (2014).

As classificações referentes à presença de mata ciliar não atenderam ao esperado no ponto 3 por $35 \%$ dos grupos $(n=7)$, possivelmente por se tratar de uma área em transição entre vegetação herbácea e arbustiva.

Presença de lixo não atendeu ao resultado esperado nos pontos 1 e 2 . No ponto 1 havia presença moderada de lixo e, portanto, deveria ser atribuída nota 3. No entanto, $90 \%$ dos grupos $(\mathrm{n}=18)$ atribuíram nota zero, interpretando qualquer presença de lixo como impacto ao ambiente. Tal compreensão pode ser favorável ao desenvolvimento de boas atitudes ambientais, porém não atendeu ao esperado para este protocolo. No segundo ponto, $65 \%$ dos grupos $(n=13)$ atribuíram nota zero e a frequência esperada era de $70 \%$ dos grupos $(n=14)$. Entretanto, 4 grupos atribuíram nota 5 e a frequência esperada para esta nota, era de apenas 1. A aplicação dos PARs

\section{IPABH}


deve ser avaliada nos diferentes contextos, pois se trata de um método simples e subjetivo (Rodrigues et al., 2012).

Percebe-se ainda que no ponto 2 a maior parte de parâmetros não atendeu ao esperado. Tal resultado pode ser atribuído a uma avaliação pouco observadora e reflexiva por parte de alguns grupos, devido ao desconforto gerado neste local. O desmoronamento, o odor fétido e a presença de lixo e entulho, podem ter oferecido um nível de dificuldade maior aos discentes da faixa etária estudada.

Portanto, os parâmetros que precisam ser compreendidos de forma mais expressiva pelos alunos são: erosão e assoreamento; presença de plantas aquáticas; corredeiras e fluxos d'água; e, presença de mata ciliar. Similarmente, o ponto 2 por ter apresentado muitos resultados inesperados, demanda maior atenção na avaliação.

O percentual de acertos de cada grupo em cada ponto de análise permitiu mapear quais grupos tiveram dificuldades de compreensão do PAR. Dessa forma, foi possível identificar que 3 grupos do $6^{\circ}$ ano e 1 grupo do $7^{\circ}$ ano precisariam compreender melhor os itens do protocolo, pois apresentaram um percentual de acertos inferior a $50 \%$ em algum dos pontos de análise. $\mathrm{Na}$ média final dos quatro pontos, $65 \%(\mathrm{n}=13)$ dos grupos atingiram um percentual superior a $70 \%$ de acertos, correspondendo à pontuação mínima determinada para este trabalho. Os outros $35 \%$ $(\mathrm{n}=7)$ dos grupos, obtiveram um percentual de acerto, na média final, entre $58 \%$ a $69 \%$ de acertos e precisariam ter os conceitos do protocolo revisados, sobretudo nos parâmetros apontados no teste do Qui-quadrado.

1. Quanto às instruções dadas em sala, 96,6\% dos alunos acreditam ter compreendido melhor o protocolo graças a essas orientações.

2. Quanto à avaliação da bacia hidrográfica, o questionário também revelou que com o protocolo, $83,1 \%$ dos alunos se sentiram como agentes colaboradores na defesa de um rio.

3. Quanto à dificuldade de entendimento dos parâmetros, $83,1 \%$ dos alunos disse não ter dificuldade de entendimento. $\mathrm{O}$ restante manifestou dificuldade no entendimento dos parâmetros mata ciliar e erosão, corroborando o resultado apresentado no qui-quadrado de Pearson.

4. Quanto à aproximação das questões ambientais, 94,9\% dos alunos acreditam que a utilização do protocolo seja um meio para essa aproximação.

5. Quanto às ilustrações disponíveis em cada parâmetro do PAR, 93,2\% dos alunos disseram que elas ajudaram durante a avaliação em campo e durante a atribuição de notas aos parâmetros.

6. Quanto aos elementos e interações na bacia hidrográfica, 96,6\% dos estudantes disseram que a participação nesta atividade de monitoramento ambiental permitiu maior conhecimento.

7. Quanto ao treinamento prévio, $96,6 \%$ dos alunos acreditam que qualquer pessoa previamente treinada pode realizar a avaliação de uma bacia hidrográfica utilizando este PAR.

Contabilizando o percentual positivo das 7 questões, nota-se que $83 \%$ dos alunos, se sentiram familiarizados com o instrumento e tiveram interesse em trabalhar com questões ambientais, o que também foi constatado por Guimarães et al. (2012). Krupek (2010) acredita que envolver voluntários aos cuidados dos cursos d'água, lhes permite a constatação de que são seres residentes da bacia, embora ele não tenha utilizado o protocolo de avaliação de bacia hidrográfica em um trabalho educacional. 
As aulas de campo geram naturalmente uma motivação para o estudo, mas se não forem bem planejadas e organizadas pode prejudicar o objetivo do estudo, sobretudo nas séries do Ensino Fundamental. Desta forma o PAR contribuiu para a organização do estudo em campo, direcionando os olhares dos alunos, estimulando a observação para as questões ambientais e lhes atribuindo a responsabilidade da avaliação do meio.

As sugestões de melhoria do ambiente estudado, elencadas pelos alunos após levantamento dos parâmetros do protocolo que não receberam nota 5 , foram discutidas em painéis. O PAR ajudou muito, neste momento, servindo como referência para os alunos fazerem suas sugestões. Para cada item que atribuíram uma nota correspondente ao ambiente impactado ou alterado, consultavam o quadro correspondente ao natural do PAR para saberem como o ambiente deveria estar e então quais ações deveriam ser realizadas. Em conferência, foram determinadas as sugestões mais viáveis de ação, as quais estão sendo estudadas junto à escola e órgãos municipais para implementação em conjunto com a comunidade escolar. As ações sugeridas foram:

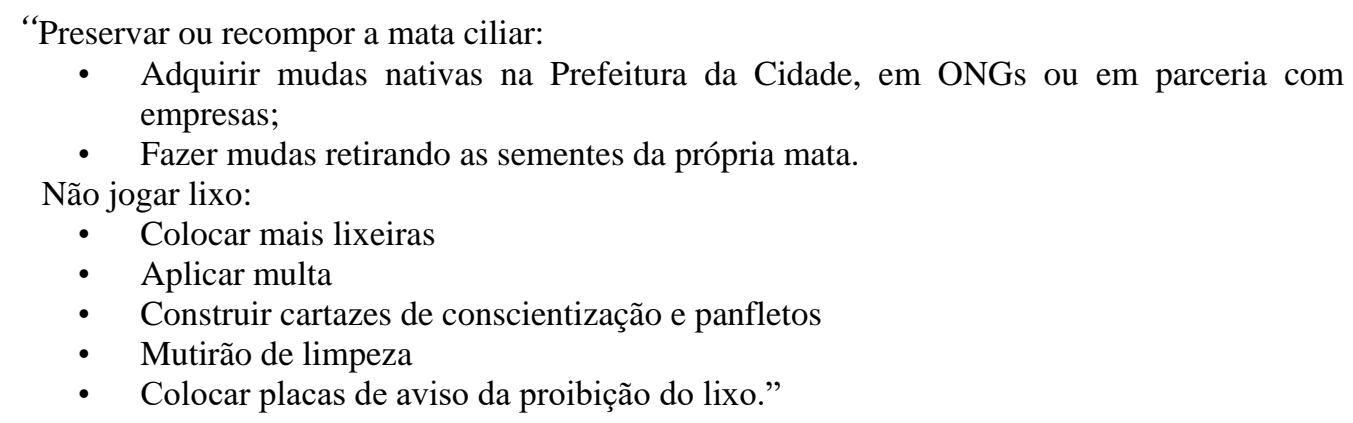

Pelas sugestões ofertadas pelos alunos e pela preocupação demonstrada por eles com a melhoria do meio onde residem pode-se constatar que o estudo da bacia, através de um instrumento didático como o PAR somado à satisfação que aulas de campo proporcionam aos alunos, pode contribuir para desenvolver a percepção ambiental, assim como já ressaltado por Bergmann (2007), e também promover um maior envolvimento dos alunos com os cuidados ambientais da cidade o que também foi constatado por Kudryavtsev et al. (2012). Tais ações podem colaborar para a educação mais significativa, formando futuros gestores em recursos hídricos (TUNDISI, 2008).

\section{CONCLUSÃO}

Constatou-se neste trabalho que o protocolo de avaliação rápida de trechos de bacia hidrográfica foi adequado para ser aplicado por alunos do Ensino Fundamental, tanto pela sequência didática assumida quanto por sua associação às aulas de campo, o que por si só gera satisfação aos alunos. Assim, constitui-se como um bom instrumento para educação ambiental, tanto no que tange ao conhecimento ambiental desenvolvido, sobretudo sobre a questão hídrica, quanto no que se refere à receptividade dos alunos em relação à atividade proposta.

A elaboração do PAR levando-se em conta as características locais próximas à unidade de ensino pode constituir um de diversos instrumentos promotores da participação social no gerenciamento dos recursos hídricos, pautados nas concepções ambientais e no desenvolvimento do significado local. Acima de tudo, deve servir como estímulo nas discussões de como a escola pode atuar de forma efetiva na gestão das águas, uma vez que ela é uma instituição fundamental nesta questão por sua natureza formadora e difusora de conhecimentos e atitudes.

Almejando alcançar melhores resultados, recomenda-se um aperfeiçoamento na metodologia nos itens relacionados à erosão, plantas aquáticas, corredeiras e fluxos d'água e mata ciliar. Acredita-se que além das atividades já propostas neste trabalho, possa ser

\section{IPABH}


desenvolvida uma atividade complementar de construção de maquete com utilização de argila, terra e plantas do jardim da escola. Os próprios alunos confeccionariam a maquete sob a orientação do professor. Assim diversos conceitos, sobretudo os que os alunos apresentaram dificuldades neste estudo, poderiam ser trabalhados de forma mais prática e concreta, contribuindo ainda mais para a ampliação da concepção ambiental.

\section{REFERÊNCIAS}

BAIÃO, C. F. P. Contribuição metodológica para ampliação da concepção ambiental no Ensino Fundamental com base no estudo de bacia hidrográfica. Dissertação (Mestrado em Ciências Ambientais). Departamento de Ciências Agrárias, Universidade de Taubaté. Taubaté, 2014.

BATISTA, G. T.; FORTES NETO, P.; DIAS, N. W.; TARGA, M. S.; OLIVEIRA, L. A. M. Educação ambiental voltada para recursos hídricos: um estudo de caso. p. 1-20, 2005. Disponível em: http://www.agro.unitau.br:8080/dspace/bitstream/2315/61/1/ Ed_Amb_Rec_Hid_Dspace.pdf Acesso em 10/06/2014.

BERGMANN, M.; PEDROZO, S. Explorando a bacia hidrográfica na escola: contribuições à Educação Ambiental. Ciência e Educação, v. 14, n. 3, p. 537-553, 2008.

BERGMANN, M. Análise da percepção ambiental da população ribeirinha do Rio Santo Cristo e de estudantes e professores de duas escolas públicas, município de Giruá, RS. Dissertação (Mestrado em Ecologia). Instituto de Biociências, Universidade Federal do Rio Grande do Sul. Porto Alegre, 2007.

BRASIL. Lei n ${ }^{\circ}$ 9433, de 8 de janeiro de 1997. Política Nacional de Recursos Hídricos. Diário Oficial da República Federativa do Brasil, Brasília, DF, 08 jan. 1997. Disponível em http://www.planalto.gov.br/ccivil_03/leis/L9433.htm Acesso em: 18/06/2012.

BRASIL. Lei n ${ }^{\circ}$ 9795, de 27 de abril de 1999. Política Nacional de Educação Ambiental. Diário Oficial da República Federativa do Brasil, Brasília, DF, 27 abril 1999. Disponível em http://www.planalto.gov.br/ccivil_03/Leis/L9795.htm Acesso em: 18/06/2012.

BRASIL. Secretaria de Educação Fundamental. Parâmetros curriculares nacionais: terceiro e quarto ciclos: apresentação dos temas transversais / Secretaria de Educação Fundamental - Brasília: MEC/SEF, 1998. 436 p. Disponível em: http://portal.mec.gov.br/seb/arquivos/pdf/ttransversais.pdf Acesso em: 12/02/2014

CALlisto, M.; FERREIRA, W. R.; MORENO, P.; GOULART, M.; PETRUCIO, M. Aplicação de um protocolo de avaliação rápida da diversidade de habitats em atividades de ensino e pesquisa (MG-RJ). Acta Limnol. Bras., v. 14, n. 1, p. 91-98, 2002.

COPPETEC, Fundação - Laboratório de Hidrologia e Estudos de Meio Ambientais. Plano de Recursos Hídricos da Bacia do Rio Paraíba do Sul - Resumo Caderno de Ações Área de Atuação do CBH-PS. 2007. Disponível em: http://www.ceivap.org.br/downloads/cadernos/CBH-PS-completo.pdf Acesso em: 30/07/2015.

CURUTCHET, G.; GRINBERG, S.; GUTIÉRREZ, R. A. Degradación ambiental y Periferia Urbana: Un Estudio Transdiciplinario sobre la Contaminación en la Región Metropolitana de Buenos Aires. Ambiente \& sociedade, v. XV, n. 2, p. 173-194, 2011.

FLORENZANO, T. G. Iniciação em Sensoriamento Remoto. São Paulo: Oficina de Textos, 2007. p. 98-99 
GUIMARÃES, A.; RODRIGUES, A. S. D. L.; MALAFAIA, G. Adequação de um protocolo de avaliação rápida de rios para ser usado por estudantes do ensino fundamental. Revista Ambient. Água, v. 7, n. 3, p. 241-260, 2012. http://dx.doi.org/10.4136/ambi-agua.996

JACOBI, P. Educação ambiental, cidadania e sustentabilidade. Cadernos de Pesquisa, v. 118, p. 189-205, 2003.

KRUPEK, A. R. Análise comparativa entre duas bacias hidrográficas utilizando um protocolo de avaliação rápida da diversidade de habitats. Ambiência - Revista do Setor de Ciências Agrárias e Ambientais, v. 6, n. 1, p. 147-158, 2010.

KUDRYAVTSEV, A.; KRASNY, M. E.; SDEDMAN, R. C. The impact of environmental education on sense of place among urban youth. Ecosphere, v. 3, n. April, 2012.

LUCATTO, L. G.; TALAMONI, J. L. B. A construção coletiva interdisciplinar em educação ambiental no ensino médio : a microbacia hidrográfica do ribeirão dos peixes como tema gerador. Ciência e Educação, v. 13, n. 3, p. 389-398, 2007.

MAKINODAN, D. Y.; COSTA, S. M. F. DA C. Estudo das características socioeconômicas e ambientais da microbacia do Rio Comprido. In: XIV Encontro Nacional de Estudos Populacionais. Anais eletrônicos... Caxambu: ABEP, 2004. Disponível em http://www.abep.nepo.unicamp.br/site_eventos_abep/PDF/ABEP2004_95.pdf Acesso em: 22/06/2012.

PORTO, M. F. A.; PORTO, R. L. L. Gestão de bacias hidrográficas. Estudos avançados, v. 22, n. 63, p. 43-60, 2008.

RODRIGUES, A. S. L.; CASTRO, P. de T. A. Protocolos de Avaliação Rápida : Instrumentos Complementares no Monitoramento dos Recursos Hídricos. RBRH - Revista Brasileira de Recursos Hídricos, v. 13, n. 1, p. 161-170, 2008.

RODRIGUES, A. S. L.; MALAFAIA, G.; COSTA, A. T.; NALINI-JÚNIOR, H. A. Adequação e avaliação da aplicabilidade de um Protocolo de Avaliação Rápida na bacia do rio Gualaxo do Norte, Leste-Sudeste do Quadrilátero Ferrífero, MG, Brasil. Revista Ambient. Água, v. 7, n. 2, p. 231-244, 2012. http://dx.doi.org/10.4136/ambi-agua.872

SCATENA, L. M. Ações em Educação Ambiental; Análise Multivariada da Percepção Ambiental de Diferentes Grupos Sociais como Instrumentos de Apoio à Gestão de Pequenas Bacias - Estudo de Caso da Microbacia do Córrego da Capituva, Macedônia, SP. Tese (Doutorado em Hidráulica e Saneamento Ambiental). Escola de Engenharia de São Carlos, Universidade de São Paulo, 2005.

SCHIEL, D.; MASCARENHAS, S.; VALEIRAS, N.; SANTOS, S. A. M.(Org.) O Estudo de Bacias Hidrográficas - Uma estratégia para Educação Ambiental. Ed. Rima: São Carlos, 2002.

SHEPARDSON, D. P.; WEE, B.; PRIDDY, M.; SCHELLENBERGER, L. What Is a Watershed? Implications of Student Conceptions for Environmental Science Education and the National Science Education Standards. Science Education, v. 91, p. 574-578, 2007.

TUNDISI, J. G. Recursos Hídricos no futuro: problemas e soluções. Estudos avançados, v. 22, n. 63, p. 7-16, 2008.

VIEIRA, S. Introdução à Bioestatística. 4 ed. Rio de Janeiro: Elsevier, 2008.

\section{IPABH}

Rev. Ambient. Água vol. 11 (suplemento) Taubaté, 2016 